REVISTA ARA N${ }^{4}$. OUTONO+INVERNO, 2018 • GRUPO MUSEU/PATRIMÔNIO FAU-USP

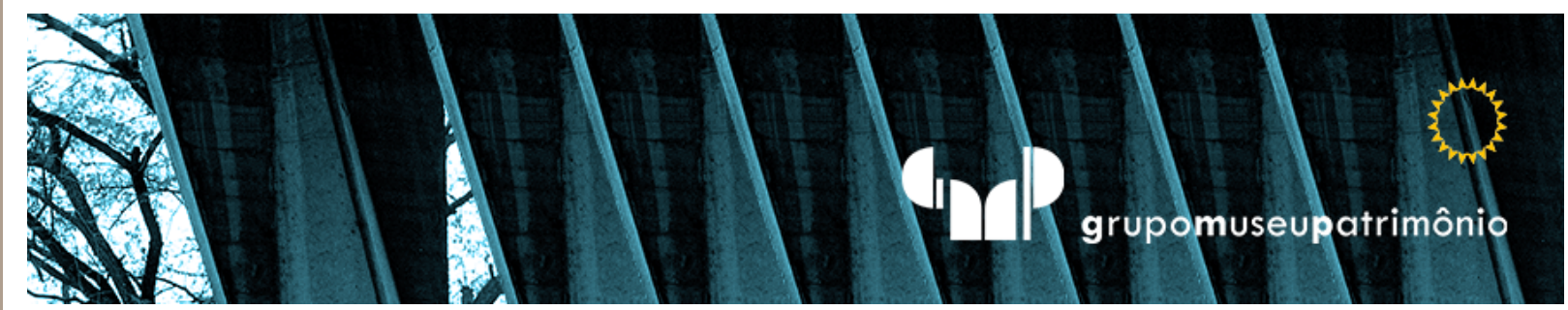

\title{
O lugar da casa-museu
}

\author{
El lugar de la casa-museo
}

\section{The place of the house-museum}

\begin{abstract}
Paulo Eduardo Barbosa
Arquiteto. Doutorando da Faculdade de Arquitetura e Urbanismo.

Universidade de São Paulo.

Membro do Grupo Museu/ Patrimônio. São Paulo, Brasil, pauloarqbarbosa@gmail.com.
\end{abstract}




\section{Resumo}

Neste artigo procuro relacionar o conceito de lugar, como proposto pelo geógrafo Milton Santos em diferentes momentos de sua produção acadêmica, à possibilidade de construção de um olhar às casas-museu, cujo foco em sua arquitetura e domesticidade permita reconhecê-las como documento de certa fricção entre a casa e a cidade.

Palavras-chave: arquitetura. Casa-museu. Lugar. Cidade.

\section{Resumen}

En este artículo intento relacionar el concepto de lugar, como propuesto por el geógrafo Milton Santos en diferentes momentos de su producción académica, a la posibilidad de construcción de una mirada a las casas-museo, cuyo foco en su arquitectura y domesticidad permite reconocerlas como documento de cierta fricción entre la casa y la ciudad.

Palabras clave: arquitectura. Casa-museo. Lugar. Ciudad.

\section{Abstract}

In this article, I try to relate the concept of place, as proposed by the geographer Milton Santos at different moments of his academic production, to the possibility of casting a glance at the house museums, whose focus on architecture and domesticity allows them to be recognized as a document of certain friction between the house and the city.

Keywords: architecture. House-museum. Place. City. 


\title{
DE CASA A MUSEU
}

Cada lugar é, à sua maneira, o mundo. Milton Santos

\begin{abstract}
A s casas-museu são um tipo específico de instituição museal que conformam, no Brasil como em muitos países, uma extensa rede de instituições espalhada por todo o território nacional, em cidades de diferentes escalas e complexidades, constituindo um conjunto de grande diversidade. São casas de escritores, pintores, líderes comunitários, artistas, personagens históricas que, por algum motivo, foram alçadas à condição de patrimônio, preservadas em condições bastante heterogêneas e abertas à visitação. Levantamento recente ${ }^{1}$ aponta mais de trezentas unidades museais no Brasil que poderiam se caracterizar como casas-
\end{abstract}

\footnotetext{
${ }^{1}$ Ver Ana Cristina Carvalho 2013.
} 
museu, segundo critérios estabelecidos por comitê específico do ICOM (International Council of Museums) ${ }^{2}$.

A instituição de uma casa-museu responde, em cada caso, às mais diversas iniciativas demarcadas por características que poderiam ser consideradas comuns ao grupo que inclui, no Brasil, por exemplo, desde a casa de Chico Mendes, em Xapuri, no estado do Acre, ao Museu da República, no Palácio do Catete, no Rio de Janeiro. Destacarei aqui entre estas similaridades, malgrado a obviedade, o fato de terem sido, em grande número, instaladas em edificações construídas originalmente para fins residenciais e que hoje atendem a uma função pública, própria dos museus na atualidade 3 .

Os objetivos destas instituições, expressos pela ação de seus dirigentes e pelos raros planos museológicos, frequentemente se propõem a materializar um enredo de vida privada que pouco desafia as expectativas relativas às personagens públicas que homenageiam, operando uma reiteração muitas vezes edulcorada de aspectos disseminados pela história oficial.

Entretanto, sua implantação em edifícios originalmente residenciais impõe questões condicionantes à necessária adaptação, relativas à manutenção predial, à iluminação, à exposição, às áreas técnicas para conservação de acervos, acessos e facilidades para o público, entre outras. As adequações, ademais, deveriam em princípio considerar e lidar de maneira cautelosa com elementos constituintes de uma certa domesticidade, embora se trate de espaço museal. Criar condições adequadas às atividades que os museus desenvolvem na atualidade, com foco em diferentes públicos e recepções

2DEMHIST (Demeures historiques-musées, Comité International pour les demeures historiquesmusées) é o comitê específico do ICOM para as casas-museu e sua criação em 1998 responde à demanda das instituições museais instaladas em casas históricas e palácios europeus, pela especificidade na definição de critérios e políticas museológicas. Houve uma grande expansão deste comitê no sentido de sua mundialização, que o obrigou a contemplar diversas escalas de casas-museu.

3De início, os museus ocidentais, cujo marco fundador é o museu denominado, Ashmoleam da Universidade de Oxford, Reino Unido, criado em 1683, eram frequentados apenas por público especializado, enquanto o Museu do Louvre, aberto em 1793 na cidade de Paris, será o primeiro dedicado a todos os cidadãos. 
diversas, implica em conservar na casa-museu, entre outros fatores, escalas de ambientes residenciais, distribuição de mobiliário compatibilizada com percursos e, ainda que a proposição expressa pelo projeto museológico não seja a da mimese e haja uma compreensão ampliada capaz de desobrigar o compromisso de reconstituição fiel dos ambientes domésticos, há sempre os limites do edifício, que como acervo constitui um item a ser preservado, a despeito das necessidades impostas pelo novo uso.

O projeto arquitetônico, quando eventualmente ocorre ser utilizado, tem se mostrado eficiente ferramenta de articulação destas demandas na busca de configurar espaços que possam contribuir com o cumprimento da missão preconizada pelo $\mathrm{ICOM}^{4}$, respeitando a condição de preservação destas edificações e seus jardins, espaços de complexidades singularizadas pelo lugar, dada a qualidade de conexão que estabelecem entre paisagem local e massa edificada.

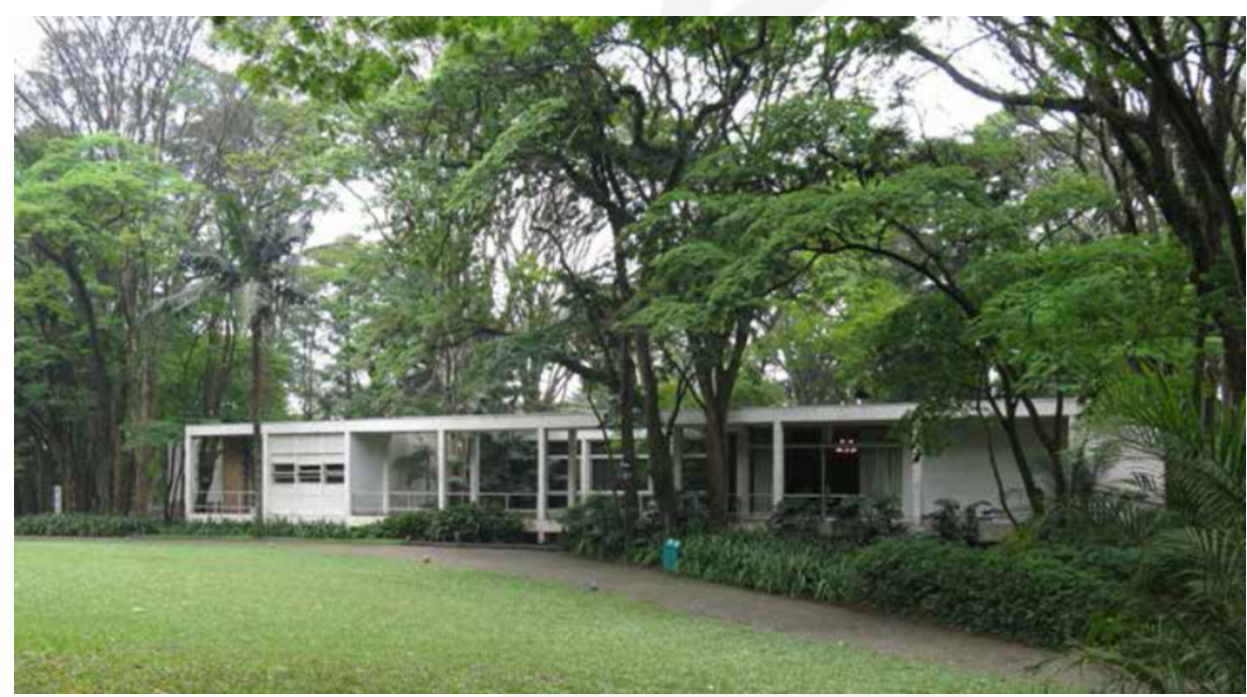

Figura 1: Casa Oscar Americano, Morumbi, São Paulo. Residência projetada por Oswaldo Bratke, construída em 1951, e o jardim projetado e executado por Otávio Augusto Teixeira Mendes, um cuidadoso trabalho de reconstituição da flora autóctone de São Paulo em área da antiga fazenda de chá Clarice. (Foto do autor)

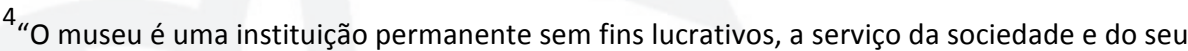
desenvolvimento, aberta ao público, que adquire, conserva, investiga, comunica e expõe o patrimônio material e imaterial da humanidade e do seu meio envolvente com fins de educação, estudo e deleite."
} 


\section{O que lembrar e o que esquecer em uma casa}

Ocorre incluir ao escopo da arquitetura e do urbanismo para além dos desafios listados, a perspectiva de observar e analisar a condição de documento atribuída a estas residências, lugar urbano no bairro e seus jardins por meio da pesquisa acadêmica, de modo a contribuir com o conhecimento de certa relação entre a casa e a cidade observando diferentes momentos desta em fricção com a permanência do edifício e sua implantação inferida pela condição de visibilidade e acesso público da nova função.

As casas-museu se valem usualmente de estratégia de congelamento do tempo como procedimento, muitas vezes reproduzindo composição de ambientes que já não mais existiam por meio de simulacros fundamentados em imagens, cujas fontes podem ser documentação fotográfica ou mesmo texto literário. Entretanto, este edifício de caráter residencial tem que se prover de espaços para acolhimento e uso dos visitantes, áreas técnicas e administrativas. Os espaços para implantação destas facilidades são itens do programa de adaptação arquitetônica e quando não construídos em forma de acréscimos à edificação original, com o risco de descaracterização do conjunto existente, evidenciam em muitos casos a opção pela reificação da personagem homenageada, pela seleção dos ambientes a desconfigurar, suprimir, operando algo como um esquecimento ativo na visão de Jean Louis Déotte ${ }^{5}$.

Alguns exemplos em São Paulo de casas-museu que optaram por eliminar cozinhas $^{6}$ no processo de transformação de seus usos atestam a construção da memória por apagamentos, da qual fala o autor francês. Curioso observar que,

\footnotetext{
5 Jean Louis Déotte (1946), filósofo, professor na Universidade de Paris, pesquisa as ditaduras latino-americanas e museus, e propõe a ideia de esquecimento ativo em que afirma que a construção da memória se vale de processos de apagamento.

${ }^{6}$ A entrada de visitantes na sede da Fundação Ema Klabin, situado na rua Portugal, bairro Jardim Europa, se dá, hoje, pelo ambiente que abrigava originalmente a cozinha da antiga residência. Enquanto, a área de cozinha e de despensa da residência Oscar Americano, no bairro do Morumbi, foi transformada em sala de exposições. Já, a cozinha da casa Guilherme de Almeida, no bairro do Sumarezinho, transformou-se em área administrativa.
} 
para que um projeto de nova construção residencial seja aprovado na prefeitura de São Paulo, necessariamente deve apresentar em sua planta baixa uma pia, num ambiente denominado cozinha, ou será cadastrado como outra categoria (de espaço comercial ou de serviços) tornando-o sujeito a diferentes alíquotas de tributação e regras edilícias.

\section{Lugar e espaço}

Orientando minha proposição neste artigo de debater uma categoria de análise que poderia contribuir à compreensão da casa-museu como testemunho da relação casa e cidade: o lugar, escolhi fazê-lo a partir das discussões de Milton Santos ${ }^{7}$, em texto de 1996, sobre a centralidade do método em Ciências Sociais cujas categorias analíticas e instrumentos de análise deveriam "por definição, ser internos ao objeto correspondente" (Santos 2017, p.22 [1996]). Muitas das análises efetuadas por Santos acerca desta categoria se prestam para configurar um debate sobre a fricção casa e cidade expressa na casa-museu.

\footnotetext{
${ }^{7}$ Milton Santos bacharelou-se em Direito na Universidade Federal da Bahia em 1948 e titulou-se doutor em Geografia pela Universidade de Strasbourg (1958), com orientação do Prof. Jean Tricart. Atuou no serviço público brasileiro, primeiramente como professor e depois ocupou cargos públicos no governo baiano, como representante da Casa Civil na Bahia durante a presidência de Jânio Quadros, no início dos anos 1960. Emigrou para a Europa em função do golpe militar em 1964 e tornou-se professor convidado nas universidades de Toulouse, Bordeaux e Paris-Sorbonne, e no IEDES (Instituto de Estudos do Desenvolvimento Econômico e Social). Seguiu sua carreira internacional no MIT (Massachusetts Institute of TechnologyBoston) como pesquisador; e como professor convidado nas universidades de Toronto (Canadá), Caracas (Venezuela), Dar-es-Salam (Tanzânia) e Columbia University (Nova lorque). Retornou ao Brasil em 1977 e voltou a lecionar na Universidade Federal do Rio de Janeiro, de 1979 a 1983 , ano em que ingressou por concurso na Universidade de São Paulo, onde permaneceu até sua aposentadoria compulsória. Foi professor convidado na Faculdade de Arquitetura e Urbanismo da Universidade de São Paulo entre 1978 e 1982. Tornou-se Professor Emérito da USP em 1997 e seguiu pesquisando, publicando e orientando até o final da vida em 2001. Publicou inúmeros artigos capítulos e cinquenta livros, entre eles Les Villes Du Tiers Monde, em 1971, na França, em que observou a expansão urbana do ponto de vista da demanda populacional dos migrantes; Por uma Geografia Nova, em 1978, no Brasil, em que o espaço é definido como uma instância social ativa, introduzindo a noção de formação sócio espacial, e
}

A Natureza do Espaço, em 1996 (Prêmio Jabuti, 1977, na categoria Ciências Humanas), em que articula conceitos e categorias com que trabalhou em sua extensa produção acadêmica. 
O conceito de lugar para o autor se desloca da posição apresentada em 1978 na qual discutiu a precedência deste em relação ao conceito de espaço, afirmando que:

[...] se de um ponto de vista puramente psicológico, o conceito de lugar nos é imposto antes do conceito de espaço, do ponto de vista teórico e epistemológico, o conceito de espaço precede o conceito de lugar. (Santos, 1978, p.121)

Propõe, ainda, a ideia de lugar como porção discreta de espaço total recorrendo a Aristóteles e a Einstein, conceituando o espaço a partir de campo e não de matéria. No mesmo texto de 1978, sistematizando os conceitos de fixos e fluxos, considera que:

[...] o espaço se define como um conjunto de formas representativas de relações sociais do passado e do presente e por uma estrutura representada por relações sociais que estão acontecendo diante dos nossos olhos e que se manifestam através de processos e funções." (Santos, 1978, p.122)

E, completa o autor, que o lugar seria "uma porção da face da terra identificada por um nome" e o que o torna específico, um objeto material, um corpo ou um grupo de objetos materiais (Santos, 1978, p. 121).

No texto de 1996 volta a discutir a categoria lugar num esforço de delimitação da disciplina, partindo da afirmação de que descrição e explicação são inseparáveis, sustentando que uma ausência de definição clara de espaço foi responsável pelo esgotamento desta temática por sobrarem exemplos que segundo ele "podem ter valor demonstrativo, mas não explicativo do papel do lugar e do espaço no processo social" (Santos, 2017, p.19 [1996]).

A reflexão que Milton Santos constrói sobre o par lugar e espaço permite contemplar a casa-museu na condição de fixo e o processo museal como fluxo, entendido aqui como constitutivo do urbano, na acepção de Henri Lefebvre que distingue a cidade, realidade presente e imediata, dado arquitetônico, do urbano, que seria uma realidade social composta de relações a serem concebidas, construídas ou reconstruídas pelo pensamento. 


\section{Casa, museu e técnicas}

A materialidade de uma casa testemunha, para além das condições de sua produção, modos de habitar e de ver o mundo, intrinsecamente ligados à cultura da cidade, revelando o protagonismo do lugar. Lugar ao qual Milton Santos reputa a impossibilidade de homogeneização à realidade dos territórios e contingências do meio associado, como resistência ao domínio do mundo expresso por relações de sobreposição cultural e econômica.

Ao considerar as técnicas como um conjunto de meios instrumentais e sociais com os quais o homem realiza sua vida, produz e, ao mesmo tempo, cria espaço, a compreensão do conceito de lugar por Milton Santos se modifica na direção daquela que "[...] atribui às técnicas o princípio de realidade histórica, relativizando o seu uso, integrando-as num conjunto de vida, retirando-as de sua abstração empírica e Ihes atribuindo efetividade histórica" ( Santos, 2017,p.58 [1996]).

É assim que a construção da casa Guilherme de Almeida ${ }^{8}$, residência do poeta paulista - em pleno período da Segunda Guerra Mundial e restrição de importação de cimento, ferro e outros materiais que supriam a demanda por conforto da classe média no período - só foi possível por recorrer a soluções criativas para sua conclusão, obrigando o uso de caixilhos mais simples e materiais locais. As casas são a expressão do lugar de que fala o geógrafo e, neste caso, ao mesmo tempo, a personagem homenageada é constitutiva da urbanidade cosmopolita de São Paulo na primeira metade do século XX, tendo desempenho social protagonista na história da cidade.

\footnotetext{
${ }^{8}$ Guilherme de Almeida (1890-1969), escritor, poeta, tradutor, pioneiro na crítica cinematográfica no Brasil, membro fundador da Revista Klaxon, para a qual desenhou a capa do no1, atuou decisivamente na Semana de Arte Moderna de 1922 ao lado de Di Cavalcanti, Mário e Oswald de Andrade. Membro da Academia Paulista e Brasileira de Letras, participou ativamente do movimento constitucionalista de 1932, conforme estudou em dissertação de mestrado, Aline Ulrich, Sua casa na Rua Macapá, no bairro do Sumarezinho em São Paulo, foi comprada pelo Governo do Estado de São Paulo em 1974 e tornou-se museu em 1979.
} 


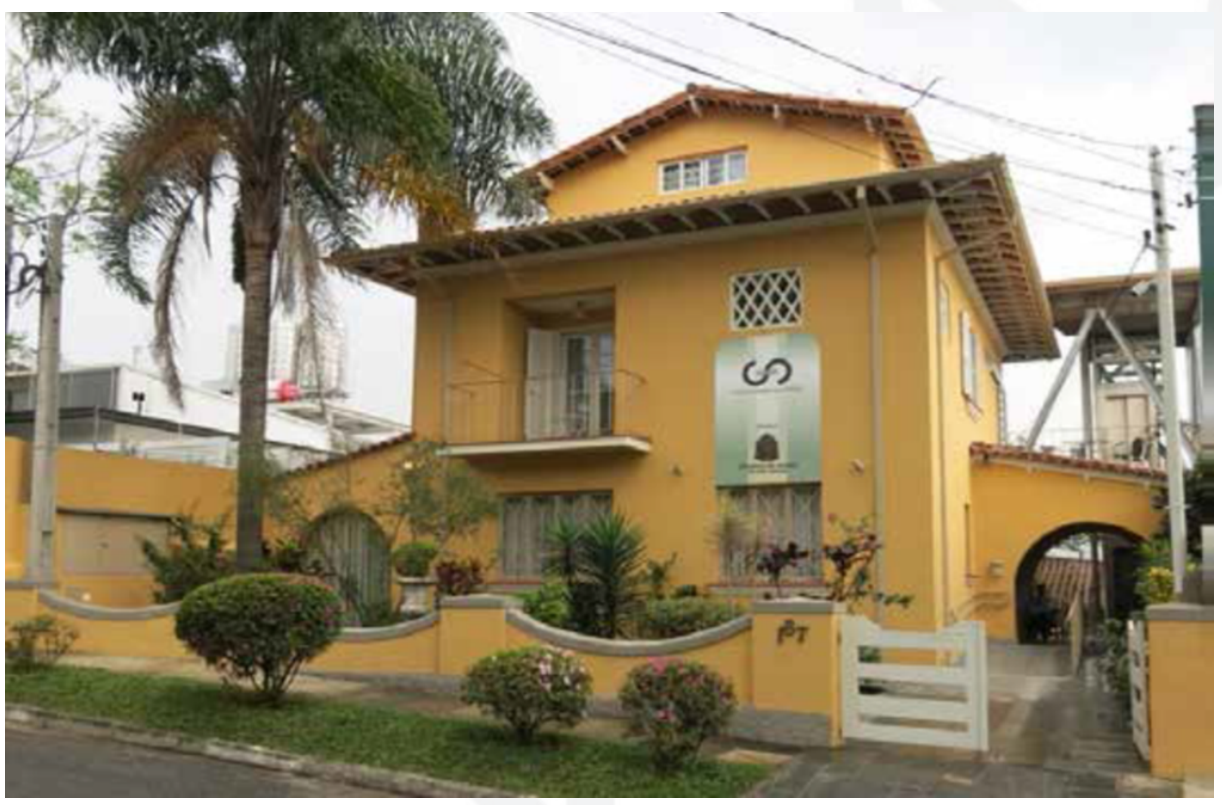

Figura 2 Fachada da Casa Guilherme de Almeida no bairro do Sumaré, São Paulo. Recente reforma, no ano de 2011, equipou a casa-museu de um elevador para tornar o pavimento superior acessível, obedecendo à norma brasileira NBR9050. O acesso à mansarda, entretanto, ainda permanece restrito. (Foto do autor)

“Cada lugar é, à sua maneira, o mundo" (Santos, 2017, p.314 [1996]). Frase com a qual Milton Santos procura apreender essa nova realidade do lugar "[...] imerso numa comunhão com o mundo, torna-se exponencialmente diferente dos demais" (Santos, 2017, p.314 [1996]) e, relatando a redescoberta da dimensão local, recoloca a consideração do cotidiano como categoria da existência que se presta a um tratamento geográfico do mundo vivido, pensando em termos de objetos, ações, técnica e tempo.

Ao descrever a universalização e a economia do espaço na obra de 1978, Milton Santos já antevia o processo de globalização em curso ao afirmar que:

[...] nossos lares são invadidos [...] por bens de cuja origem às vezes não podemos mesmo desconfiar. Tudo que nos circunda traz a marca dessa internacionalização devorante e mesmo o nosso corpo, pelo que o envolve, não escapa a essa mundialização. (Santos, 1996, p.168 [1978])

Adiante, no mesmo texto, chama esse processo de universalização perversa posto que discrimina e aumenta a riqueza e poder de alguns e a pobreza e 
fragilidade da imensa maioria, mas já apontava que há "uma receptividade específica dos lugares, ocupados e vazios, aos fluxos de modernização ou inovação" (Santos, 1978, p.212 [1996]), sendo o ambiente doméstico, apresentado pelas casas-museu, o palco destas transformações.

\section{Casa-museu, ação e memória.}

Milton Santos descreve o papel da proximidade, pensada agora não como definição de distâncias, mas como "contiguidade física entre pessoas numa mesma extensão, num mesmo conjunto de pontos contínuos, vivendo com a intensidade de suas inter-relações" (Santos, 2017, p.318 [1996]), criando solidariedade, laços culturais e, desse modo a identidade. Refere-se à cidade como:

[...] o lugar onde há mais mobilidade e mais encontros, potencializados nos países subdesenvolvidos pelo menor coeficiente de racionalidade na operação da máquina urbana. (Santos, 2017, p.319 [1996]),

Santos acentua ainda que a cidade constitui o espaço da criação de uma cultura popular que assume uma revanche contra a cultura de massas, e que no lugar, a vida social se individualiza. O autor torna os contornos conceituais do lugar mais precisos ao afirmar que:

\footnotetext{
O lugar é o quadro de uma referência pragmática ao mundo, do qual the vêm solicitações e ordens precisas de ações condicionadas, mas é também o teatro insubstituível das paixões humanas, responsáveis, por meio da ação comunicativa pelas mais diversas manifestações da espontaneidade e da criatividade. (Santos, 2017, p.322[1996])
}

O autor vê a cidade encontrar um caminho para o futuro na sua condição de diversidade social que produz diversidade espacial, observando que se de um lado "[...]a cidade grande é onde os fracos podem subsistir" a difusão do capital 
novo está reservada ao campo. Os pobres na metrópole do terceiro mundo ${ }^{9}$ convergem em guetos urbanos que "comparados a outras áreas da cidade, tenderiam a dar às relações de proximidade um conteúdo comunicacional ainda maior "[...] são eles que "[...] abrem um debate novo, inédito [...] com as populações e as coisas já presentes" (Santos, 2017, p.324 [1996])

A ideia de desterritorialização é inserida pelo autor constatando que a mobilidade torna-se uma regra no final do século passado e afirmando que a circulação é mais criadora que a produção quando tudo passa a mudar de lugar: os homens, as mercadorias, as ideias, os produtos, as imagens. A cidade seria a sede de uma vigorosa alienação, habitada por homens que não a criaram, que não conhecem sua história. Entretanto o homem ainda assim, mora, fixa residência, e é assim que os migrantes precisam criar, segundo Santos, uma terceira via de entendimento da cidade, porque para eles a memória é inútil, travam um embate entre o tempo da ação e o tempo da memória.

O processo de integração e de entendimento se dá numa relação nova que o morador estabelece com o espaço

[...] se manifesta dialeticamente como territorialidade nova e cultura nova, que interferem reciprocamente, mudando-se paralelamente territorialidade e cultura; e mudando o homem [...]. A força deste movimento vem do fato de que, enquanto a memória é coletiva, o esquecimento e a consequente (re)descoberta são individuais, diferenciados [...]. (Santos, 2017, p.329[1996])

Curioso exemplo de casa-museu como ferramenta de integração das populações em movimento é o Van Eesteren Museum em Amsterdam, Holanda, cujo procedimento inclui uma função instrumental dada ao objeto, por meio da ação cultural do museu. Uma das unidades residenciais do conjunto habitacional, projetado em 1930 e construído em 1950, pelo

\footnotetext{
${ }^{9}$ Milton Santos utiliza a locução habitual no período, Terceiro Mundo, referindo-se aos países em desenvolvimento, portanto, já contendo a noção ampliada ao cunho econômico da expressão originalmente política que congregava os países que não se alinharam à chamada Guerra Fria.
} 
arquiteto holandês que foi presidente dos Congressos Internacionais de Arquitetura Moderna - CIAM, de 1930 a 1947, e signatário da Carta de Atenas, teve sua reconstituição original promovida como parte de um programa de acolhimento e integração social aos novos habitantes do conjunto, representados em sua maioria por imigrantes norte-africanos.

A experiência do Van Eesteren Museum não é única. Outras ações como a empreendida pelo Museu Casa de Guimarães Rosa, em Cordisburgo, junto às crianças que se apropriam do lugar sertão por meio da literatura roseana, revelam a potência que reside na transversalidade da ação da casa-museu ao deslocar-se de uma missão de reprodução anacrônica e reificante de enredos ditos oficiais na direção das novas e incertas recepções.

\section{REFERÊNCIAS BIBLIOGRÁFICAS}

Carvalho, Ana Cristina (org.). Museus-casas históricas no Brasil. São Paulo: Curadoria do Acervo Artístico-Cultural dos Palácios do Governo do Estado de São Paulo, 2013.

Déotte, Jean-Louis. Catástrofe y olvido: las ruinas, Europa, El museo. Santiago: Cuarto Proprio, 1998.

Lefebvre, Henri. O direito à cidade. Itapevi, São Paulo: Nebli, 2016.

Santos, Milton. A força do lugar (p. 313-40). In: A natureza do espaço. São Paulo: Edusp, 2017. (1996).

Uma tentativa de definição do espaço (p.113-22). In: Por uma geografia nova. São Paulo: Hucitec, 1978.

Novos rumos para a geografia brasileira (p.209-19). In: Novos rumos da geografia brasileira, Milton Santos (org.). São Paulo: Hucitec, 1981.

Ulrich, Aline. Guilherme de Almeida e a construção da identidade paulista. Dissertação de Mestrado apresentada à Faculdade de Filosofia Ciências e Letras Humanas da Universidade de São Paulo- FFLCH-USP, Departamento de Letras Clássicas e Vernáculas, 2008. 


\section{Fontes eletrônicas e sites}

Definição Museu/ Icom http://icom-portugal.org/2015/03/19/definicaomuseu/

Sobre Milton Santos www.miltonsantos.com.br/ 
